\title{
Sero-epidemiology and risk factor analysis of human brucellosis in Punjab, Pakistan: a cross sectional study
}

\author{
Nawaz, Z. ${ }^{1 *}$, Shafique, M. ${ }^{1}$, Zahoor, M.A. ${ }^{1}$, Siddique, A.B. ${ }^{1}$, Ali, S. ${ }^{2}$, Arshad, R. ${ }^{3}$, Kausar, S. ${ }^{1}$, Khan, K. ${ }^{4}$, \\ Asad, M. ${ }^{1}$, Rehman, A.U. ${ }^{1}$, Masih, I. ${ }^{1}$
}

${ }^{1}$ Department of Microbiology, Government College University Faisalabad, Punjab, Pakistan

${ }^{2}$ Veterinary Research Institute, Lahore, Punjab, Pakistan

${ }^{3}$ University College of Conventional Medicine, The Islamia University of Bahawalpur, Punjab, Pakistan

${ }^{4}$ DHQ Hospital, Bhakkar, Punjab Pakistan

*Corresponding author: zeeshannawaz@gcuf.edu.pk

\section{ARTICLE HISTORY}

Received: 24 May 2021

Revised: 18 July 2021

Accepted: 19 July 2021

Published: 30 September 2021

\begin{abstract}
Human brucellosis is a neglected zoonotic problem worldwide with a high degree of morbidity in humans and is mostly overlooked due to other febrile conditions. The aim of this study was to evaluate the sero-prevalence and risk factors of human brucellosis among subjects living in Punjab, Pakistan. In this cross-sectional study, human blood samples were collected from seven districts of Punjab, Pakistan. Information regarding personal data, demographic data and potential risk factors was collected through a structured questionnaire. Detection of anti-Brucella antibodies was done through Rose Bengal Plate Test (RBPT) and Enzyme Linked Immunosorbent Assay (ELISA). Descriptive analysis, Chi square test and Odds ratio was applied using STATA software version 12. The sero-prevalence of human brucellosis was $13.13 \%$ with significantly higher percentage in males $17.23 \%$ and age group $25-40$ years $16.50 \%(P=<0.001)$. The demographic factors positively associated with human brucellosis were lack of education $(P=0.003 ; O R=1.85)$ and farming as an occupation $(P=<0.001 ; O R=$ 2.50) Similarly, among the risk factors studied, keeping animals at home $(P=<0.001 ; O R=$ 2.03), slaughtering of animals $(P=<0.001 ; O R=15.87)$ and consuming raw milk $(P=<0.001 ; O R$ $=5.42$ ) were the factors strongly connected with human brucellosis. A massive awareness should be given to livestock farmers and individuals directly linked to animals regarding risk factors and transmission of brucellosis. Consumption of unpasteurized milk and its products should be condemned to curtail this neglected disease.
\end{abstract}

Keywords: Human brucellosis; risk factors; RBPT; ELISA; Pakistan.

\section{INTRODUCTION}

Human brucellosis also known as Mediterranean fever is one of the most prevalent zoonoses worldwide caused by member of genus Brucella. The three most common species responsible for human brucellosis are Brucella melitensis, Brucella abortus and Brucella suis (Ali et al., 2018). It is public health issue and a neglected bacterial disease infecting human beings and animals for decades. Brucellosis in animals is recognized as Bang's disease, epizootic abortion and contagious abortion (Wadood et al., 2009). Animals involved in its zoonotic transmission are goats/sheep, buffaloes/cattle and pigs (Mandell et al., 2010).

Human brucellosis shows variety of clinical manifestations such as intermittent fever, profuse sweating, chills, headache, weakness, arthralgia, depression, weight loss, splenomegaly and hepatomegaly. Severe cases may lead to arthritis, osteomyelitis, spondylitis, epididymitis and orchitis
(Franco et al., 2007). In endemic areas, brucellosis is among the causes of extended duration fever and often categorized as fever of unknown origin (FUO) (Attard et al., 2018).

Transmission of this infection to humans is through direct or indirect contact with infected animals and ingestion of contaminated animal products such as milk, meat, or carcasses (Makita et al., 2008). Aerosol and secretions of infected animals also act as a vehicle for human transmission (Lapaque et al., 2006). Conversely, human to human transmission is very rare (Godfroid et al., 2005). Brucellosis is a serious occupational hazard for veterinarians, animal handlers, slaughter house workers, farmers and laboratory personnel, who commonly are more exposed to animals (Pappas et al., 2005).

Brucella infection occurs more predominantly in individuals having reduced level of immunity due to stress or diseases like HIV (Al-Anazi \& Jasser, 2007). The diagnostic tests mostly used for brucellosis are the Rose Bengal 
Test (RBT), Serum Agglutination test (SAT), Standard Tube Agglutination Test (STAT), Enzyme linked immunosorbent assay (ELISA) and Polymerase chain reaction (PCR) (Godfroid et al., 2010; Saeed et al., 2019). Among all, both ELISA and agglutination tests are relatively less time consuming, more sensitive and inexpensive tests (Mantecón et al., 2006).

Studies in different areas of Khyber Pakhtunkhwa, Pakistan including Peshawar, Charsadda, Malakand, Bhimber and swat have been conducted but no epidemiological study has been conducted so far in Punjab, Pakistan elaborating the exact status regarding human brucellosis. Keeping in consideration all above mentioned facts, the present study was designed with the aim to detect the sero prevalence of human brucellosis and risk factors associated with this disease.

\section{MATERIALS AND METHODS}

\section{Ethical Approval}

This study was approved by Institutional Ethics Review Committee under code GCUF/ERC/18/03C on April 06, 2018, and the samples were collected in accordance with international safety rules and bioethics was observed during the span of the study.

\section{Study Design}

This cross-sectional study was carried out in seven major districts of Punjab, Pakistan including Bhakkar, Chiniot, Faisalabad, Gujranwala, Jhang, Sialkot and Vehari and a total of 2010 individuals were selected for sampling from January to December 2019 (Figure 1). A structured closed ended questionnaire was designed having dichotomous and multichotomous questions before sample collection based on similar published surveys. All the questionnaires were filled privately in a designated quiet room to avoid any kind of distraction or disturbance. The purpose of questionnaire was to collect information about socio-demographic factors (age, gender, education, occupation, marital status, residence and socioeconomic status) and hypothesized factors (animals at home, slaughtering of animals, milking of animals, consuming raw milk and knowledge of brucellosis) to determine their influence on the transmission of brucellosis. If a subject was illiterate and had no companion, the trained staff filled in the questionnaire on his/her behalf. To ensure confidentiality, the subject's names or medical record numbers were not obtained.

\section{Sampling Procedure and Sample Size}

The sampling was performed using non-probability convenience technique and the sample size was estimated with the formula as described by (Thrusfield, 2007).

$$
\mathrm{n}=\frac{1.96^{2} \mathrm{P} \exp (1-\mathrm{P} \exp )}{\mathrm{d}^{2}}
$$

Where ' $n$ ' is number of samples, 'Pexp' is expected prevalence and ' $d$ ' is desired absolute precision. The expected prevalence was kept at $16 \%$ and desired absolute precision at $5 \%$ (Ali et al., 2018).

\section{Inclusion Criteria and Subjects Recruitment}

The study included subjects having recent history of acute febrile illness aged 10 to 65 years. All those subjects were excluded who were below 10 years or who provided an incomplete questionnaire. During recruitment, the subjects were asked to participate in the study voluntarily. The samples were collected after obtaining verbal consent from participants and their legal guardians if the subject is below 18 years. Each subject was included after explaining them the objectives and purpose of study.

\section{Sample Collection}

A total $(5 \mathrm{~mL})$ of venous blood was collected from each subject following venipuncture by trained medical staff with sterile disposable syringes and were labeled anonymously using unique identification codes, date and location. After collection, samples were transported to serology laboratory and serum was separated from each sample followed by storage at $4^{\circ} \mathrm{C}$ till further processing.

\section{Detection of anti-Brucella antibodies}

All the serum samples were screened for detection of antiBrucella antibodies using Rose Bengal Plate Test (RBPT) and Enzyme linked immunosorbent assay (ELISA). All the samples $(n=2010)$ were first screened for anti-Brucella antibodies using RBPT and the samples that turned positive showing visible agglutination were then confirmed by IgM-ELISA test. The samples that showed positive reactions for both tests were considered as positive because no single test is suitable for all epidemiological situations as well as variation in the specificity and sensitivity of each test (OIE, 2008).

\section{Rose Bengal Plate Test (RBPT)}

The Rose Bengal Plate test (RBPT) is a rapid test which was designed initially for veterinary purpose, but now it is often used for the diagnosis of human brucellosis as well (RuizMesa et al., 2005). Firstly all the sera samples, positive and negative controls and RBPT antigen were equilibrated at room temperature followed by gentle shaking. After that $30 \mu \mathrm{l}$ of each serum sample was placed on a clean glossy white ceramic tile and equal volume of RBPT antigen was added. Both the solutions were then mixed with sterile applicator stick and the ceramic tile was gently rocked for 8-10 minutes. The presence of visible agglutination or appearance of typical rim was considered as positive result (Morgan et al., 1969).

\section{Enzyme Linked Immunosorbent Assay (ELISA)}

The ELISA was performed for detection of IgM antibodies against Brucella as described by manufacturers (NovaLisa, Novatech Immunodiagnostics, Germany). Firstly the samples were diluted and dispensed in pre-coated ELISA plates followed by dispensing of positive and negative control sera in allocated wells. About one hour incubation was provided at $37^{\circ} \mathrm{C}$ followed by washing of wells. All the wells were then filled with $100 \mu \mathrm{l} \mathrm{HRP}$ conjugated rabbit anti-human IgM antibodies except blank control and incubated for an hour. After second washing $100 \mu \mathrm{l}$ of TMB substrate was added followed by 15 minutes incubation in dark. Stop solution was added and results were recorded using ELISA reader (Multiskan Thermo Scientific, USA) at 450nm (Kalem et al., 2016).

\section{Statistical Analysis}

The data obtained from questionnaire was arranged in Microsoft Excel sheet and analyzed using STATA version 12 (Stata Corp., USA). Descriptive statistics was used to summarize the data in the form of percentages and Chi square test. P-values $<0.05$ were considered to be statistically significant. Univariate analysis was performed to establish the association of risk factors with human brucellosis and odds ratio (OR) was obtained at $95 \%$ confidence intervals (Cl) as described by (Naz et al., 2018). 


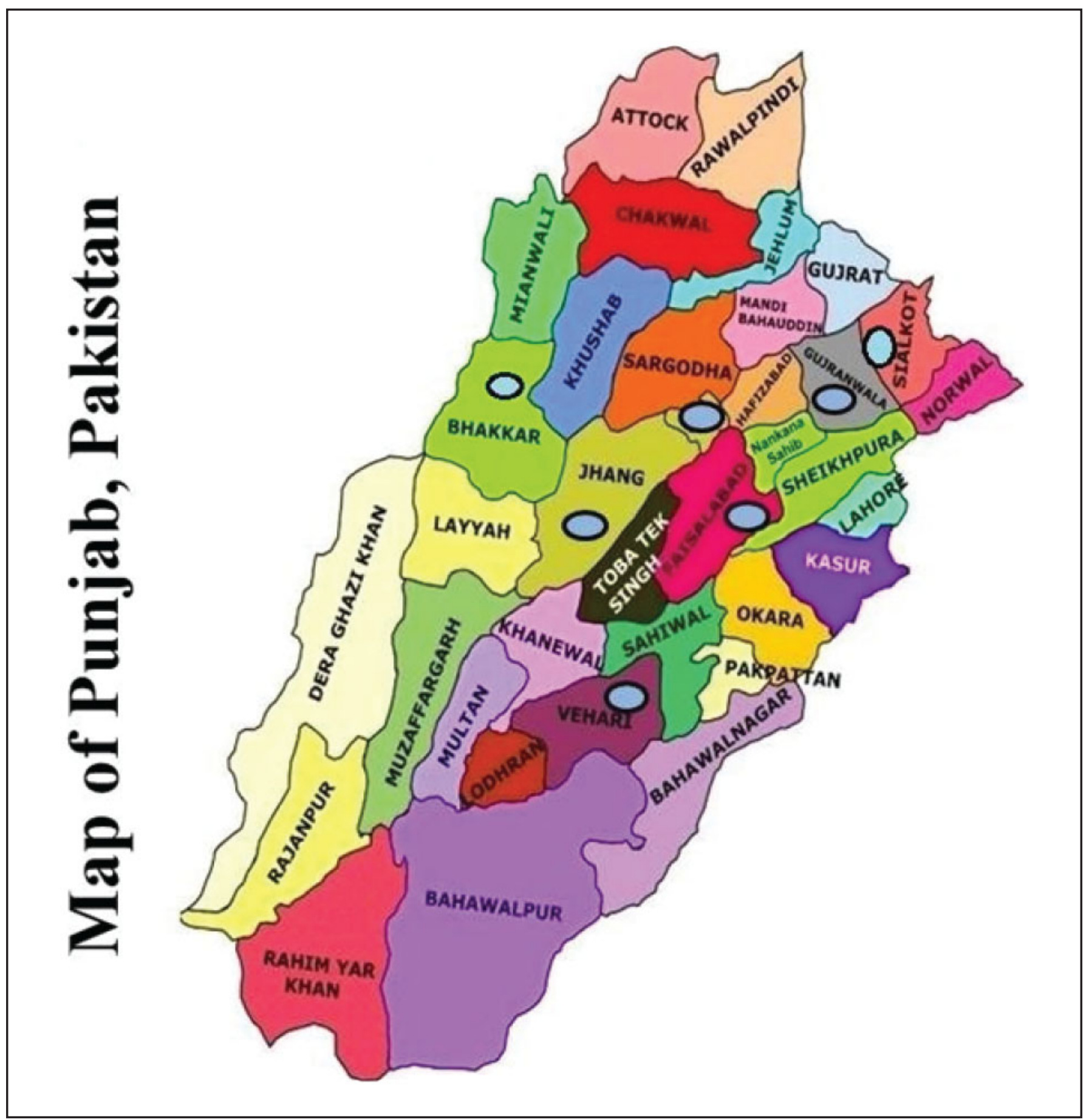

Figure 1. Map representing geographical location of study districts of Punjab, Pakistan.

\section{RESULTS}

A total of 2010 human serum samples were collected from different districts of Punjab, Pakistan during this study and 264 (13.13\%) were found to be positive for brucellosis. The prevalence of human brucellosis was detected highest in district Jhang (32.30\%) followed by Sialkot with (19.28\%) while least prevalence was found in district Gujranwala (4.75\%). The difference in the sero-prevalence of human brucellosis among different districts was found statistically significant $(P=<0.001)$ as shown in (Table 1$)$.

The sero-prevalence of human brucellosis varied among genders and it was found $17.23 \%$ in males in contrast to $8.89 \%$ in females $[\mathrm{OR}=2.13,95 \% \mathrm{Cl}=1.62-2.80]$. On the basis of
Table 1. Sero-prevalence of human brucellosis in different districts of Punjab, Pakistan

\begin{tabular}{lcccc}
\hline Area & $\begin{array}{c}\text { Total } \\
\text { Sampled }\end{array}$ & $\begin{array}{c}\text { Total } \\
\text { Positive }\end{array}$ & $\begin{array}{c}\text { Prevalence } \\
(\%)\end{array}$ & P Value \\
\hline Bhakkar & 270 & 23 & $8.52 \%$ & \\
Chiniot & 300 & 16 & $5.33 \%$ & \\
Faisalabad & 250 & 40 & $16.00 \%$ & \\
Gujranwala & 400 & 19 & $4.75 \%$ & $<0.001$ \\
Jhang & 260 & 84 & $32.30 \%$ & \\
Sialkot & 280 & 54 & $19.28 \%$ & \\
Vehari & 250 & 28 & $11.20 \%$ & \\
Total & $\mathbf{2 0 1 0}$ & $\mathbf{2 6 4}$ & $\mathbf{1 3 . 1 3 \%}$ & \\
\hline
\end{tabular}

$\mathrm{P}$ value for Chi Square test; Significant at $\mathrm{P}<0.05$. 
age highest prevalence was observed $16.50 \%$ in age group ( $25-40$ years) followed by $15.02 \%$ in (10-25 years) and $7.43 \%$ in (40-65 years) $[\mathrm{OR}=2.20,95 \% \mathrm{Cl}=1.51-3.20]$. Both gender and age were found statistically significant $(P=<0.001)$. The prevalence of human brucellosis was also detected on the basis of education and occupation status and the results showed that the education (Secondary or above) was inversely associated with human brucellosis. It was found highest among uneducated individuals (17.57\%) while lowest among those having secondary and above level of education (10.28\%) [OR=1.85, 95\% $\mathrm{Cl}=1.35-2.55]$. According to the occupation, farmers were found more prone to Brucella infection $21.21 \%$ in comparison to unemployed $11.16 \%$ and employed individuals $9.70 \%$ [OR $=2.50,95 \% \mathrm{Cl}=1.75-3.57]$. The results on the basis of education and occupation were also found statistical significant $(P<0.05)$ as shown in (Table 2 ).

The results of present study indicated that on the basis of residency, the sero-prevalence of human brucellosis was found $14.49 \%$ in rural and $11.47 \%$ in urban residents. A nonsignificant results was found between human brucellosis and residency $(P=0.080)$, marital status $(P=0.475)$ and socioeconomic status of participants $(P=0.188)$ as shown in (Table 2).

In the current study, it was found that keeping animals at home $[\mathrm{P}=<0.001(\mathrm{OR}=2.03 ; 95 \% \mathrm{Cl}=1.55-2.65)]$, slaughtering of animals $[\mathrm{P}=<0.001(\mathrm{OR}=15.87 ; 95 \% \mathrm{Cl}=10.98-22.93)]$ and consuming raw milk $[\mathrm{P}=<0.001(\mathrm{OR}=5.42 ; 95 \% \mathrm{Cl}=4.11-7.14)]$ were the factors strongly associated with human brucellosis. The percentages were found to be variable among the groups of different suspected risk factors, but statistically there was no association detected between the prevalence of human brucellosis and some variables like knowledge of brucellosis and milking of animals ( $>0.05)$ as shown in (Table 3 ).

\section{DISCUSSION}

Brucellosis is a pervasive disease of animals having zoonotic potential through direct contact with infected animals and consuming their products such as meat, milk and milk products (Ramos et al., 2008). Sero-diagnosis is considered an important tool for rapid and sensitive detection of brucellosis with special emphasis on RBPT and ELISA (Abubakar et al., 2012).

In the present study sero-prevalence of human brucellosis was reported $13.13 \%$ in different districts of Punjab, Pakistan with highest level reported in district Jhang $32.30 \%$ and least prevalence in district Gujranwala $4.75 \%$. These results are found slightly elevated than results of previous studies by (Din et al., 2013) with 9.33\% and (Perveen \& Shahid, 2015) with $10 \%$ seroprevalence in district Bhimber and Charsadda, Pakistan respectively. In contrast, the current findings were lower than the results of $23.30 \%$ by (Madut et al., 2018) in Sudan, $17 \%$ by (Tumwine et al., 2015) in Uganda and $18 \%$ by (Arvas et al., 2013) in Turkey. This variation in the seroprevalence of human brucellosis in different districts of Punjab is due to the difference in livestock population, environmental conditions, personal protection methods used to deal with animals and trend of consuming pasteurized dairy products (Ducrotoy et al., 2014).

The sero-prevalence of human brucellosis was higher in males $17.23 \%(176 / 1021)$ as compared to females $8.89 \%$ (88/989). These results are in accordance with $12 \%$ in males and $9 \%$ in females by (Perveen \& Shahid, 2015) and 24\% in males and $8 \%$ in females by (Ali et al., 2018) in Pakistan. Similarly, in Uganda $20.5 \%$ in males and $15.3 \%$ in females was reported by (Tumwine et al., 2015) and in Saudi Arabia a research finding also showed that human brucellosis is

Table 2. Sero-prevalence of human brucellosis according to demographic factors

\begin{tabular}{|c|c|c|c|c|c|}
\hline Variables & Total Sampled & Total Positive (\%) & Chi Square Test ( $P$ Value) & Crude Odds Ratio & $95 \% \mathrm{Cl}$ \\
\hline \multicolumn{6}{|l|}{ Gender } \\
\hline Male & 1021 & $176(17.23 \%)$ & $<0.001$ & 2.13 & $(1.62-2.80)$ \\
\hline Female & 989 & 88 (8.89\%) & & & \\
\hline \multicolumn{6}{|l|}{ Age } \\
\hline $10-25$ Years & 539 & $81(15.02 \%)$ & & & \\
\hline 25-40 Years & 812 & $134(16.50 \%)$ & $<0.001$ & 0.89 & $(0.66-1.20)$ \\
\hline 40-65 Years & 659 & 49 (7.43\%) & & 2.20 & $(1.51-3.20)$ \\
\hline \multicolumn{6}{|l|}{ Education status } \\
\hline Uneducated & 535 & $94(17.57 \%)$ & & & \\
\hline Primary & 678 & $88(12.97 \%)$ & 0.003 & 1.42 & $(1.04-2.95)$ \\
\hline Secondary or above & 797 & $82(10.28 \%)$ & & 1.85 & $(1.35-2.55)$ \\
\hline \multicolumn{6}{|l|}{ Occupation Status } \\
\hline Farmer & 476 & 101 (21.21\%) & & & \\
\hline Unemployed & 967 & $108(11.16 \%)$ & $<0.001$ & 2.14 & $(1.59-2.88)$ \\
\hline Employed & 567 & 55 (9.70\%) & & 2.50 & $(1.75-3.57)$ \\
\hline \multicolumn{6}{|l|}{ Residence } \\
\hline Rural & 1104 & $160(14.49 \%)$ & 0.080 & 1.30 & $(1.00-1.70)$ \\
\hline Urban & 906 & $104(11.47 \%)$ & & & \\
\hline \multicolumn{6}{|l|}{ Marital status } \\
\hline Married & 1164 & $159(13.65 \%)$ & 0.475 & 1.11 & $(0.85-1.45)$ \\
\hline Unmarried & 846 & 105 (12.41\%) & & & \\
\hline \multicolumn{6}{|l|}{ Socioeconomic status } \\
\hline Low & 911 & 135 (14.81\%) & & & \\
\hline Middle & 609 & $74(12.15 \%)$ & 0.188 & 1.25 & $(0.92-1.70)$ \\
\hline High & 490 & 55 (11.22\%) & & 1.37 & $(0.98-1.92)$ \\
\hline
\end{tabular}

$P$ value for Chi Square test; Significant at $P<0.05$. 
Table 3. Sero-prevalence of human brucellosis according to risk factors

\begin{tabular}{|c|c|c|c|c|c|}
\hline Risk factors & Total Sampled & Total Positive (\%) & Chi Square Test (P Value) & Crude Odds Ratio & $95 \% \mathrm{Cl}$ \\
\hline \multicolumn{6}{|c|}{ Animals at home } \\
\hline Yes & 951 & $165(17.35 \%)$ & $<0.001$ & 2.03 & $(1.55-2.65)$ \\
\hline No & 1059 & 99 (9.34\%) & & & \\
\hline \multicolumn{6}{|c|}{ Slaughtering of animals } \\
\hline Yes & 147 & 91 (61.90\%) & $<0.001$ & 15.8 & $(10.98-22.93)$ \\
\hline No & 1863 & $173(20.04 \%)$ & & & \\
\hline \multicolumn{6}{|c|}{ Milking of animals } \\
\hline Yes & 485 & 77 (15.87\%) & 0.074 & 1.35 & $(1.01-1.80)$ \\
\hline No & 1525 & $187(12.26 \%)$ & & & \\
\hline \multicolumn{6}{|c|}{ Consuming Raw Milk } \\
\hline Yes & 626 & $173(27.90 \%)$ & $<0.001$ & 5.42 & $(4.11-7.14)$ \\
\hline No & 1384 & $91(6.57 \%)$ & & & \\
\hline \multicolumn{6}{|c|}{ Knowledge of Brucellosis } \\
\hline Yes & 203 & $18(8.86 \%)$ & 0.090 & 1.61 & $(0.98-2.67)$ \\
\hline No & 1807 & $246(13.61 \%)$ & & & \\
\hline
\end{tabular}

$P$ value for Chi Square test; Significant at $P<0.05$.

more prominent in male subjects (Alkahtani et al., 2020). Furthermore the results of current study represents that age group ranging between 25 and 40 years was highly linked to Brucella sero-positivity (16.50\%), which resembles with the findings of (Gur et al., 2003) in Turkey, (Perveen \& Shahid, 2015) in Pakistan and (Alkahtani et al., 2020) in Saudi Arabia. The reason behind such results is that young male members are more involved in livestock farming, milking, management of animals and as veterinarians in Asian countries (Niaz et al., 2021). Another factor linked with human brucellosis was rural residency showing $14.49 \%$ prevalence in comparison to urban $11.47 \%$ which is supported by observations $21.4 \%$ in rural and $7.9 \%$ in urban areas by (Tumwine et al., 2015) and 23 $\%$ in rural and $10 \%$ in urban residents by (Ali et al., 2018). Similarly on the basis of occupation, farmers are more than two times at risk of getting brucellosis in comparison to employed $(O R=2.5)$ and unemployed individuals $(O R=2.1)$ which is also supported by (Ali et al., 2018) in Pakistan, (Nguna et al., 2019) in Uganda. The reason for such elevated level of human brucellosis in rural residents is that in Pakistan, they are more involved in livestock farming and almost every family is directly or indirectly linked with livestock (Ali et al., 2018).

The sero prevalence of human brucellosis was also examined on the basis of education status and it was observed that an inverse relationship was present between education and prevalence of brucellosis. As the level of education increases, the prevalence of brucellosis decreases. This finding is in concordance with findings of (Ali et al., 2018) in Pakistan and (Madut et al., 2018) in Sudan. Such results are due to the fact that educated individuals prefer to consume pasteurized milk and its products as well as have a concept of zoonotic disease transmission (Tumwine et al., 2015). Other factors studied were socioeconomic status and marital status of participants which were non significantly linked with human brucellosis and not studied previously.

Keeping animals at home is considered as one of the prominent factors linked with human brucellosis and the results depicts that the risk of brucellosis is twice in individuals having animals at homes $(O R=2.03)$. This fact is supported by (Tumwine et al., 2015) and similar findings were also found by (Madut et al., 2018). Correspondingly, the individuals involved in slaughtering of animals are fifteen times more prone to brucellosis as the prevalence in slaughterers is $61.90 \%$ in contrast to others $20.04 \%$. The findings of (Ali et al., 2018) showed $24 \%$ prevalence while (Madut et al., 2018) recorded $33.3 \%$ in slaughter workers. This could be attributed to the direct contact with infected animals, handling their offals and consumption of their infected products.

Consumption of raw milk was also found statistically associated with Brucella prevalence $[\mathrm{P}=<0.001 ; \mathrm{OR}=5.42]$ in our study coinciding with the research outputs of (Tumwine et al., 2015) with $(\mathrm{OR}=1.26)$ in Uganda and (Ali et al., 2018) with $(O R=2.36)$ in Pakistan. Similarly there is high resemblance found between the findings of current study and the research conducted in Palestine (Husseini \& Ramlawi, 2004) and Bangladesh (Rahman et al., 2012) which established the fact that brucellosis is transmitted by consuming contaminated animal products including butter, milk, meat, etc. (Mishal et al., 1999). On the other hand milking of animals and having knowledge of brucellosis are the factors non-significantly $(P>0.05)$ linked with human brucellosis. Nevertheless some other studies also favored these facts (Abo-Shehada et al., 1996; Tumwine et al., 2015). The milkers are frequently in direct contact with animals and the probability of carrying infection are much more in members belonging to this group.

\section{CONCLUSION}

The results of present study indicate that brucellosis is a prominent public health issue and a neglected zoonotic disease particularly in rural areas of Pakistan. Male members and farmer community are among the high risk group of this disease. This study enlighten that keeping animals at home, consumption of raw milk, direct contact with animals including slaughtering are risk factors strongly associated with humans brucellosis. Awareness about risk factors, pasteurization of milk and its products and vaccination of animals should be highly recommended to curtail the prevalence of this zoonotic disease. 


\section{ACKNOWLEDGEMENT}

The authors acknowledged the contribution of Veterinary Research Institute, Punjab, Pakistan for providing the Rose Bengal antigen used in this study.

\section{Funding}

This was a self-funded project.

\section{Conflict of interest}

The authors declare that they have no conflict of interest.

\section{REFERENCES}

Abo-Shehada, M.N., Odeh, J.S., Abu-Essud, M. \& Abuharfeil, N. (1996). Seroprevalence of brucellosis among high risk people in Northern Jordan. International Journal of Epidemiology 25: 450-454. https://doi.org/10.1093/ije/ 25.2.450

Abubakar, M., Mansoor, M. \& Arshed, M.J. (2012). Bovine brucellosis: Old and new concepts with Pakistan perspective. Pakistan Veterinary Journal 32: 147-155.

Al-Anazi, K.A. \& Al-Jasser, A.M. (2007). Brucella bacteremia in patients with acute leukemia: a case series. Journal of Medical Case Reports 1: 144. https://doi.org/10.1186/17521947-1-144

Ali, S., Nawaz, Z., Akhtar, A., Aslam, R., Zahoor, M.A. \& Ashraf, M. (2018). Epidemiological investigation of human brucellosis in Pakistan. Jundishapur Journal of Microbiology 11: e61764. https://doi.org/10.5812/jjm.61764

Alkahtani, A.M., Assiry, M.M., Chandramoorthy, H.C., Al-Hakami, A.M. \& Hamid, M.E. (2020). Sero-prevalence and risk factors of brucellosis among suspected febrile patients attending a referral hospital in southern Saudi Arabia (2014-2018). BMC Infectious Diseases 20: 26-30. https:// doi.org/10.1186/s12879-020-4763-z

Arvas, G., Akkoyunlu, Y., Berktas, M., Kaya, B. \& Aslan, T. (2013). The prevalence of brucellosis in adults in Northeastern Region of Turkey. Jundishapur Journal of Microbiology 6: 262264. https://doi.org/10.5812/jjm.5147

Attard, L., Tadolini, M., De Rose, D.U. \& Cattalini, M. (2018). Overview of fever of unknown origin in adult and paediatric patients. Clinical and Experimental Rheumatology 36: $10-24$

Din, A.M.U., Khan, S.A., Ahmad, I., Rind, R., Hussain, T., Shahid, M. \& Ahmed, S. (2013). A study on the seroprevalence of brucellosis in human and goat populations of district Bhimber, Azad Jammu and Kashmir. The Journal of Animals and Plant Sciences 23: 113-118.

Ducrotoy, M.J., Bertu, W.J., Ocholi, R.A., Gusi, A.M., Bryssinckx, W., Welburn, S. \& Moriyón, I. (2014). Brucellosis as an emerging threat in developing economies: Lessons from Nigeria. PLoS Neglected Tropical Diseases 8: e3008. https:// doi.org/10.1371/journal.pntd.0003008

Franco, M.P., Mulder, M., Gilman, R.H. \& Smits, H.L. (2007). Human brucellosis. Lancet Infectious Diseases 7: 775-786. https://doi.org/10.1016/S1473-3099(07)70286-4

Godfroid, J., Cloeckaert, A., Liautard, J.P., Kohler, S., Fretin, D., Walravens, K., Bastuji, B.G. \& Latesson, J.J. (2005). From the discovery of the Malta fever's agent to the discovery of a marine mammal reservoir, brucellosis has continuously been a re-emerging zoonosis. Veterinary Research 36: 313-326. https://doi.org/10.1051/vetres: 2005003
Godfroid, J., Nielsen, K. \& Saegerman, C. (2010). Diagnosis of brucellosis in livestock and wildlife. Croatian Medical Journal 51: 296-305. https://doi.org/10.3325/cmj.2010.51.296

Gur, A., Geyik, M.F., Dikici, B., Nas, K., Cevik, R., Sarac, J. \& Hosoglo, S. (2003). Complications of brucellosis in different age groups: a study of 283 cases in Southeastern Anatolia of Turkey. Yonsei Medical Journal 44: 33-44. https://doi.org/10.3349/ymj.2003.44.1.33

Husseini, A.S. \& Ramlawi, A.M. (2004). Brucellosis in the West Bank, Palestine. Saudi Medical Journal 25: 1640-1643.

Kalem, F., Ergün, A.G., Durmaz, S., Doğan, M., Ertuğrul, Ö. \& Gündem, S. (2016). Comparison of a new and rapid method: Brucella Coombs Gel Test with other diagnostic tests. Journal of Clinical Laboratory Analysis 30: 756-759. https://doi.org/10.1002/jcla.21934

Lapaque, N., Forquet, F., de Chastellier, C., Mishal, Z., Jolly, G. \& Moreno, E. (2006). Characterization of Brucella abortus lipopolysaccharide macrodomains as mega rafts. Cell Microbiology 8: 197-206. https://doi.org/10.1111/j.14625822.2005.00609.x

Madut, N.A., Nasinyama, G.W., Muma, J.B., Sube, K.L.L., Ocan, M. \& Muwonge. A. (2018). Prevalence of brucellosis among patients attending Wau Hospital, South Sudan. PLOS One 13: e0199315. https://doi.org/10.1371/journal.pone. 0199315

Makita, K., Fevre, E.M., Waiswa, C., Kaboyo, W., Bronsvoort, B.M.D.C., Eisler, M.C. \& Wellburn, S.C. (2008). Human brucellosis in urban and peri-urban areas of Kampala, Uganda. Annals of New York Academy Sciences 1149: 309-311. https://doi.org/10.1196/annals.1428.015

Mandell, G.L., Bennett, J.E. \& Dolin, R. (2010). Principles and practice of infectious diseases, $7^{\text {th }}$ edition. Churchill Livingstone: Elsevier, pp. 2921-2926

Mantecón, M.Á., Gutiérrez, P., Del Pilar Zarzosa, M., Duenas, A.I., Solera, J. \& Fernández-Lago, L. (2006). Utility of an immunocapture-agglutination test and anenzyme-linked immunosorbent assay test against cytosolic proteins from Brucella melitensis B115 in the diagnosis and follow-up of human acute brucellosis. Diagnostic Microbiology and Infectious Disease 55: 27-35. https://doi.org/10.1016/ j.diagmicrobio.2005.11.003

Mishal, J., Ben-Israel, N., Levin, Y., Sherf, S., Jafari, J., Embon, E. \& Sherer, Y. (1999). Brucellosis outbreak: analysis of risk factors and serologic screening. International Journal of Molecular Medicine 4: 655-658. https://doi.org/10.3892/ ijmm.4.6.655

Morgan, W.J., MacKinnon, D.J., Lawson, J.R. \& Cullen, G.A. (1969). The rose bengal plate agglutination test in the diagnosis of brucellosis. Veterinary Records 85: 636-641. https:// doi.org/10.1136/vr.85.23.636

Naz, A., Nawaz, Z., Rasool, M.H. \& Zahoor, M.A. (2018). Cross sectional epidemiological investigations of Giardia lamblia in children in Pakistan. Sao Paulo Medical Journal 136: 449-453.

Nguna, J., Dione, M., Apamaku, M., Majalija, S., Mugizi, D.R., Odoch, T. \& Kato, C.D. (2019). Seroprevalence of brucellosis and risk factors associated with its seropositivity in cattle, goats and humans in Iganga District, Uganda. Pan African Medical Journal 33: 99. https://doi.org/10.11604/ pamj.2019.33.99.16960

Niaz, S., Raqeeb, A., Khan, A., Nasreen, Amir, S., Zhu, L. \& Kumar, S. (2021). Status of human brucellosis in district Malakand, Khyber Pakhtunkhwa, Pakistan. Journal of Infection and Public Health 14: 423-427. https://doi.org/ 10.1016/j.jiph.2019.12.013 
OIE (2018). A Manual of Diagnostic Tests and Vaccines for Terrestrial Animals. Paris: Office international des epizooties, 2008: 14.

Pappas, G., Akritidis, N., Bosilkovski, M. \& Tsianos, E. (2005). Brucellosis. New England Journal of Medicine 352: 2325-2336. https://doi.org/10.1056/NEJMra050570

Perveen, F. \& Shahid, M. (2015). Sero-prevalence of brucellosis in humans population of Charsasdda, Khyber Pakhtunkhwa, Pakistan. International Journal of Medical Investigation 4: 232-240.

Rahman, A.K., Dirk, B., Fretin, D., Saegerman, C., Ahmed, M.U., Muhammad, N., Hossain, A. \& Abatih, E. (2012). Seroprevalence and risk factors for brucellosis in a high-risk group of individuals in Bangladesh. Foodborne Pathogens and Disease 9: 190-197. https://doi.org/10.1089/fpd. 2011.1029

Ramos, T.R.R., Junior, P., Wilton, J., Sobrinho, M., Santana, P.A. \& Santana, V.L.A. (2018). Epidemiological aspects of an infection by Brucella abortus in risk occupational groups in the micro region of Araguaína, Tocantins. Brazilian Journal of Infectious Diseases 12: 133-138. https://doi.org/ $10.1590 / \mathrm{s} 1413-86702008000200007$
Ruiz Mesa, J.D., Sánchez Gonzalez, J., Reguera, J.M., Martín, L., Lopez Palmero, S. \& Colmenero, J.D. Rose Bengal test: diagnostic yield and use for the rapid diagnosis of human brucellosis in emergency departments in endemic areas. Clinical Microbiology and Infection 11: 221-225. https:// doi.org/10.1111/j.1469-0691.2004.01063.x

Saeed, U., Ali, S., Khan, T.M., El-Adawy, H., Melzer, F., Khan, A.U., Iftikhar, A. \& Neubauer, H. (2019). Seroepidemiology and the molecular detection of animal brucellosis in Punjab, Pakistan. Microorganisms 7: 449. https://doi.org/ 10.3390/microorganisms 7100449

Thrusfield, M.V. (2007). Surveys. In: Veterinary Epidemiology, 3rd edition. lowa: Blackwell Publishers, pp. 228-242.

Tumwine, G., Matovu, E., Kabasa, J.D., Owiny, D.O. \& Majalija, S. (2015). Human brucellosis: sero-prevalence and associated risk factors in agro-pastoral communities of Kiboga District, Central Uganda. BMC Public Health 15: 900. https://doi.org/10.1186/s12889-015-2242-z

Wadood, F., Ahmad, M., Khan, A., Gul, S.T. \& Rehman, N. (2009). Seroprevalence of brucellosis in horses in and around Faisalabad. Pakistan Veterinary Journal 29: 196-198. 